A Review Paper

\title{
On Mars there was Water
}

\author{
Florian Ion Tiberiu Petrescu \\ ARoTMM-IFToMM, Bucharest Polytechnic University, Bucharest, (CE), Romania
}

Article history

Received: $25-04-2018$

Revised: 26-04-2018

Accepted: 09-05-2018

Email: scipub02@gmail.com

\begin{abstract}
Scientists overseeing Curiosity's mission on Mars confirmed that the shape and size of the pebbles on the dry tracks indicate that they were transported and eroded by the waters. According to them, the rover found the roots of rocks equivalent to the flowing waters on Earth. The planet Mars, the closest to Terra, had life conditions similar to our blue planet and although some of them have been degraded, there are still traces of their existence as if they would invite us to visit it, we study it closely and arrange it for support the life. It can be said that the moment of the beginning of the colonization of the planet Mars by mankind is very close. Such a long-awaited and desirable event will certainly represent a major objective of our planet and humanity. Anything as difficult as any is harder until it starts. Then it will go on its own, with success and with possible falls, but it is important that it will finally start.
\end{abstract}

Keywords: Mars, Propulsion Systems, Modern Aerospace Vehicles, Energy, Power, Impulses, Accelerated Ions, Accelerated Electrons, Photons, LASER

\section{Introduction}

Recently NASA published the surprise proof of Curiosity that on Mars was water (NASA publishes Curiosity's surprising evidence that there was water on Mars). The material is based on a photograph taken by NASA's Red Curiosity Rover, which can be observed even today with extremely old sediments proving that in a distant past, the surface of Mars has water. "These rocks show us that in the past it was warmer on Mars and so wet that water flowed on the surface of the planet," said Linda Kah, who worked on analyzing the images made by the Curiosity Rover on Mars (Fig. 1).

New evidence from NASA's Mars Reconnaissance Orbiter (MRO) revealed that the entire network of melted snowfalls and springs were on Mars much earlier than researchers had imagined.

Based on the new images made on the ancient, northern region of Mars, researchers said there was a "considerable amount of water" about a billion years before the "wet age" of the red planet to end.

This reveals that the planet was suitable for microbial life for a much longer time than the researchers estimate.

"We have discovered valleys that carry water to the lakeside basins," said a team member, Sharon Wilson of the Smithsonian Intitle. "Some lakes full of lakes indicate that there was a considerable amount of water in those times," she added.

Wilson and his team analyzed the images recorded in the northern area of Mars, called Arabia Terra (an extremely eroded area known as one of the oldest areas of the planet).

Researchers have been able to identify signs of water evaporating long ago. "One of the lakes in the region can be compared as much as Lake Tahoe," Wilson said.

The researcher explained that this lake was fed by a Martian valley south out of jelly in the north and pouring a large pool called Heart Lake (Fig. 2), (On Mars there was water billions of years before scientists considered the phenomenon possible; Science Alert, 16 SEP 2016).

Heart Lake is part of the entire system of lakes and valleys that stretch 150 kilometers along the north of the planet. The team estimated that the lake could support 2,790 cubic miles of water. Drawing on the information gathered from 22 craters in the area, the team concluded that these lakes were two or three billion years ago. During this time the snow melted in each season could feed all areas with water.

Researchers said they had found such formations in other parts of Mars, but north and south of the equator the wetlands were much more extensive (Science Alert, 16 SEP 2016).

Lakes and snow on Mars formed much later than previously thought, according to new findings, using primary data from Mars Reconnaissance Orbiter at NASA.

Recently discovered lakes and streams appeared about one billion years after an old, documented and old swamp. These results provide an insight into the climate history of the red plan and suggest that surface conditions at that later date might have been appropriate for microbial life. 


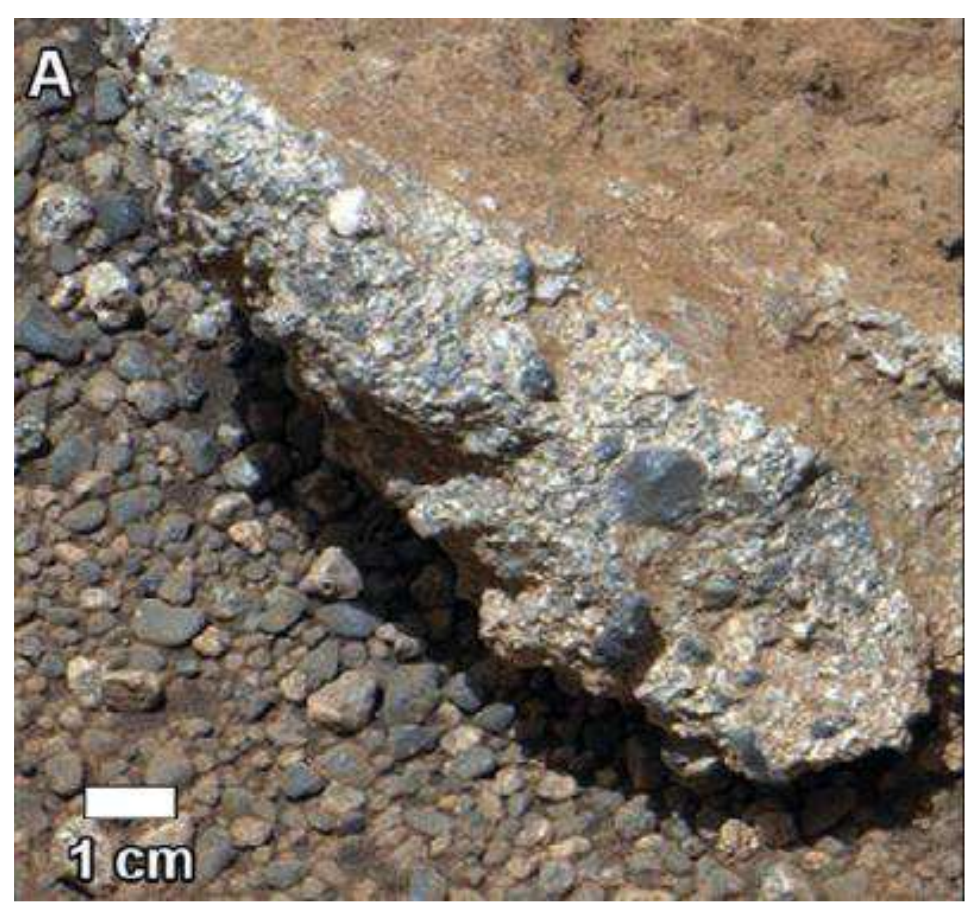

Fig. 1: A photograph taken by NASA's Red Curiosity Rover

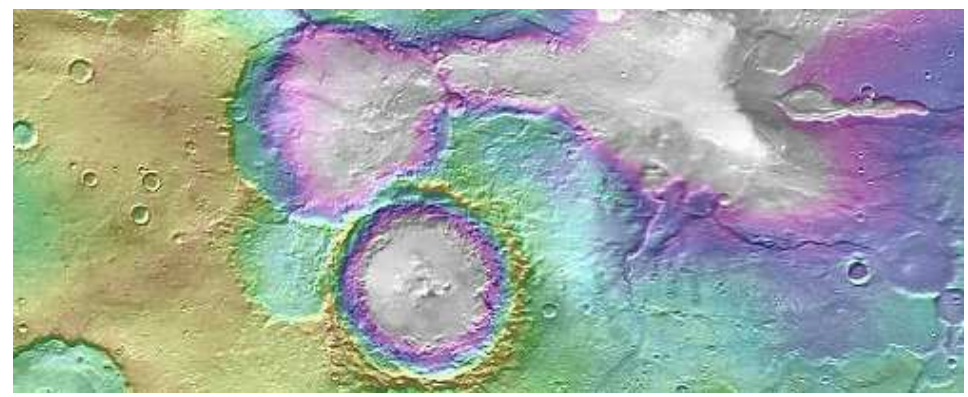

Fig. 2: This Lake was fed by a Martian valley south out of jelly in the north and pouring a large pool called Heart Lake

"We have discovered valleys that have transported water into the lakes," said Sharon Wilson of the Smithsonian Institute in Washington and the University of Virginia, Charlottesville. "Some pond basins were filled and flooded, indicating that at that time there was a considerable amount of water on the landscape."

Wilson and colleagues have found evidence of these features in the Terra North region by analyzing images in the contextual hall and large experiment rooms on the Marbi Reconnaissance Orbiter and additional data from Mars Global Surveyor and Mars Express.

"One of the lakes in this region was comparable in volume with Lake Tahoe," Wilson said, referring to a California-Nevada lake that holds about 45 kilometers of water. "This Martian lake was fed by an entry valley on its southern edge and floated along its northern edge, carrying water downstream into a huge, full of water, nicknamed Lake Heart."
The chain of lakes and valleys that are part of the Valley of the Heart system extends to about 90 kilometers. Researchers calculate Lake Heart held about 670 kilometers of water (2790 cubic kilometers), more than in Lake Ontario in the Great Lakes of North America.

Wilson and co-authors of the report in Geophysical Research Journal, Planet, describe the extent of the flow in "freshly superficial valleys" and their former associated lakes. They suggest that the drains that form the valleys could have been seasonal.

To cover the time when Terraced Valleys, scientists began with age estimates for 22 impact craters in the area. They evaluated whether the valleys carved in the remains of the boxes as a value indicator higher or lower than the craters. They concluded that this relatively wet period on Mars was probably between two and three billion years ago, after much of the planet's initial atmosphere was considered to be lost and most of the water that left the planet was frozen (Bujor, 2016). 
The surface of the valley supports the interpretation that the climate was cold: "The rate at which the water flows through these valleys is consistent with the melted snow droplets," Wilson said, "they did not grow, had drainage patterns and did not form deep, such as the old valleys at the beginning of Mars."

They note that similar valleys meet elsewhere on Mars between approximately 35 and 42 degrees latitude, both north and south of the equator. The similar appearance and widespread nature of these fresh and superficial valleys on Mars suggest that they have formed rather globally than at local or regional level.

"A key objective for exploring Mars is to understand when and where liquid water was present in a volume sufficient to change the Martian surface and provide life," said Rich Zurek, a researcher at the NASA Jet Propulsion Laboratory Pasadena, California. "This paper presents evidence of water episodes that alter the surface of early Mars, perhaps hundreds of millions of years later than previously thought, with some implication that the water was made of snow, not rain."

The findings will likely determine more studies to understand how the conditions have warmed enough on the frozen planet to allow a range of flowing waters. One possibility could be an extreme change in the inclination of the planet, with a more direct illumination of polar ice.

Wilson's co-authors are Alan Howard of the University of Virginia; Jeffrey Moore of NASA Ames Research Center, Moffett Field, California; and John Grant of Smithsonian. Scientists overseeing Curiosity's mission on Mars confirmed that the shape and size of the pebbles on the dry tracks indicate that they were transported and eroded by the waters. According to them, the rover found the roots of rocks equivalent to the flowing waters on Earth. (Science Alert, 16 SEP 2016).

\section{Materials and Methods}

If you can live on Mars or live on this planet, it's a natural question. The population of our planet has far exceeded the boundaries from which the planet begins to overburden. Global resources are diminishing and their consumption is growing more and more. The world's population is growing, it needs housing, food, water, air, clothes, transport, energy and the possibilities offered by our planet are getting smaller. Because we have moved a lot from the chapter "conquering space", we consider limiting the existing resources for present and future populations and for those who want to expand into desert waters or areas. In order to conquer the cosmic space with the current technologies, a sustained financial effort is needed, but unfortunately it is not at the level of necessity. Under these circumstances, it is natural to ask whether there is a possibility of living on Mars, which is a subject of great interest for astrobiology due to the proximity of the planet and its similarities to the Earth
(Bujor, 2016). So far, no concrete evidence has been found about past or present existence on Mars, but the evidence now proves that during the ancient nightlife, the surface of the planet had liquid water and could be useful for microorganisms. Of course, the existence of living conditions does not necessarily imply the presence of life.

The scientific evidence of life's evidence began in the nineteenth century and continues today through telescopic investigations and landings. If early studies focused on phenomenology and were limited to fantasy, modern scientific research highlighted the search for water, soil and surface biosignals and biomarker in the atmosphere. On November 22, 2016, NASA reported that it found a large amount of underground ice in the Utopia Planet area of Mars. The volume of water detected was estimated to be equivalent to the volume of water in the Upper Lake.

Mars has a special interest in studying the origins of life because of its resemblance to the Early Earth. This is especially true because Mars has a cold climate and does not have a tectonic plate or a derived continent, so it remained almost unchanged since the end of the Hesperian period. It can be said that at least two-thirds of Mars's surface is 3.5 billion years and Mars can have the best data on prebiotic conditions that lead to abiogenesis, even if life does not exist or has never been there. In May 2017, evidence of the earliest known life on earth can be found in the 3.48 billion-year geyserite and other related mineral deposits (mostly located around springs and ice) found in Craton Pilbara, Australia West. Such newly discovered evidence might be useful to decide where to look for the best signs on Mars.

On January 24, 2014, NASA reported that Curiosity vehicles and Mars Opportunity began looking for evidence of their previous lives, including a biosphere based on autotrophic, chemotrophic or chemolithoototrophic microorganisms and on old water (including the Australian River or the Old Lakes) could have been habitable. More recently, searching for evidence of habitats, taphonomy (fossil-related) and organic carbon on Mars is now a major objective of NASA.

In July 2017, researchers reported that the surface of Mars might be more toxic to microorganisms, especially for a common type of Bacillus subtilis, as originally believed in a Martian perturic study of a Martian similar to UV.

On September 5, 2017, scientists reported that Curiosity Rover on Mars detected boron, an essential ingredient for life on Earth. Such a discovery, along with previous discoveries of the fact that liquid water was clearly present on the ancient Mars, still supports Mars's possible adaptation to life.

ESA initially estimated ExoMars projects at around 1 billion euros ( $\$ 1.3$ billion), but NASA's withdrawal in the 2012-2013 project and the subsequent reorganization of associations will probably add several hundred million euros. 
Thus, the Member States instructed the Director of the Agency to look at how this deficit could be achieved. One possibility is that other ESA scientific activities will be closed, modified, postponed so that the funds originally allocated to them reach the ExoMars project, so ExoMars will become a priority. Since September 2012 it has been announced that part of the additional amount will be covered by attracting new members to the project and new members already proposed, Poland and Romania, will contribute 70 million euros for the ExoMars mission.

As a last resort for the ExoMars project, ESA did not rule out the possibility of returning the US and NASA to the program as a full or partial partner somewhere until 2018 if US policy changes with the change of leadership. This possibility is not yet certain, its funding has been seen as a supplement and additional help.

ExoMars funding by Russia could be partly covered by insurance payments of 1.2 billion rubles ( $\$ 40.7$ million) for the loss and reallocation of Phobos-Grunt funds for eventual coordination between Mars-NET and ExoMars.

On January 25, 2013, Roscosmos fully funded the development of the scientific tools to be launched at the first launch, Trace Gas Orbiter (TGO).

Since March 2014, the British Airbus Defense and Space division has begun to acquire critical components, but the 2018 mission has still been frustrated by over $\$$ 100 million or Canadian Canadian payments of \$ 138 million suspended by the Canadian Space Agency and manufactured by MDA Corporation Canada).

Although it was obvious that the loss of US support was great for the project and even its destruction, this project for mankind was saved by Europe, Russia, England and Canada, who managed to make the huge shock to the Americans, asking former President Obama . It sometimes happens that a man can change the destiny of humanity for good or evil, but even if it is now the loss of an essential project for mankind, with the intervention of one man, Obama, here is the combined support of Great Britain, Europe, Russia and Canada. saved the project on time.

What followed was released on March 14, 2016 (Livestream started at 08:30 GMT [3:30 AM EDT]). Four missiles took place within the next $10 \mathrm{~h}$ before the descent module and the orbiter could be released. Thus, the signal from Orbiter was successfully received at 21:29 GMT of the same day, which confirmed that the launch was successful and that the spacecraft is heading to Mars. Shortly after the probe separation, the Briz-M support tools exploded a few kilometers away, apparently without affecting the orbit or soil. The spacecraft, which hosted Trace Gas Orbiter and Schiaparelli, took a nominal orbit on Mars and seemed to be in service. Over the next two weeks, controllers continued to verify and make available their systems, including propulsion systems, communications, star tracking and navigation and guidance.
Recent models have shown that, even with a dense $\mathrm{CO}_{2}$ atmosphere at the beginning of March, it was colder than it ever was on Earth. It is believed that weather conditions caused by heat or volcanism could have created favorable conditions for the formation of the latest late wind grid, even if the afternoon weather of the nobles was probably frozen. Although it seems that the local warming of the environment through volcanism and impact would have been sporadic, there would have been many water events flowing towards Mars. So, both mineralogical and morphological evidence clearly and clearly indicates that the Hesperian medium-sized habitats were degraded on Mars. Exact causes are not yet well understood, but can be correlated with a combination of processes, including early atmospheric loss or impact erosion, or both.

Basically, what truly supports life on Tera is, first of all, the magnetic field of the Earth, which then sustains all other defense systems of our planet. The loss of the Martian magnetic field has obviously influenced surface environments through atmospheric losses and increased radiation; this change significantly degraded the surface habitats. As long as there is a magnetic field, the atmosphere on Mars would have been protected from solar wind erosion, which would ensure the maintenance of a dense atmosphere necessary for the existence of liquid water on the surface of Mars. The loss of the magnetic field and then the Martian atmosphere, all living conditions on the planet have been degraded. Loss of the atmosphere was accompanied by lower temperatures. Some of the liquid water inventory was sublimated and transported to the poles, while the rest was caught in permafrost, a layer of underground ice. Another part of the water and the atmosphere have returned or lost. Obviously, studying what happened on Mars, we find other data about the degradation of living conditions on any planet, with the loss of its magnetic field, followed by the loss of the atmosphere.

Field observations and numerical modeling have shown that the impact of crater formation can lead to the creation of a long-lasting hydrothermal system when ice is present in the crust. For example, a $130 \mathrm{~km}$ long crater could sustain an active hydrothermal system up to 2 million years to produce a microscopic life (Fig. 3); The crater of the algae is considered to have impact glass depots that could have kept the old biosignees if they were under impact.

Earth and stone samples that were explored in (NASA, 2013) vessels the curiosity tools have provided additional information about multiple habitats.

The Rover team has identified some of the main chemical ingredients for life in this soil, including sulfur, nitrogen, hydrogen, oxygen, phosphorus and possibly carbon, as well as clay minerals, suggesting a durable aqueous medium - or an old salty river - neutral. 


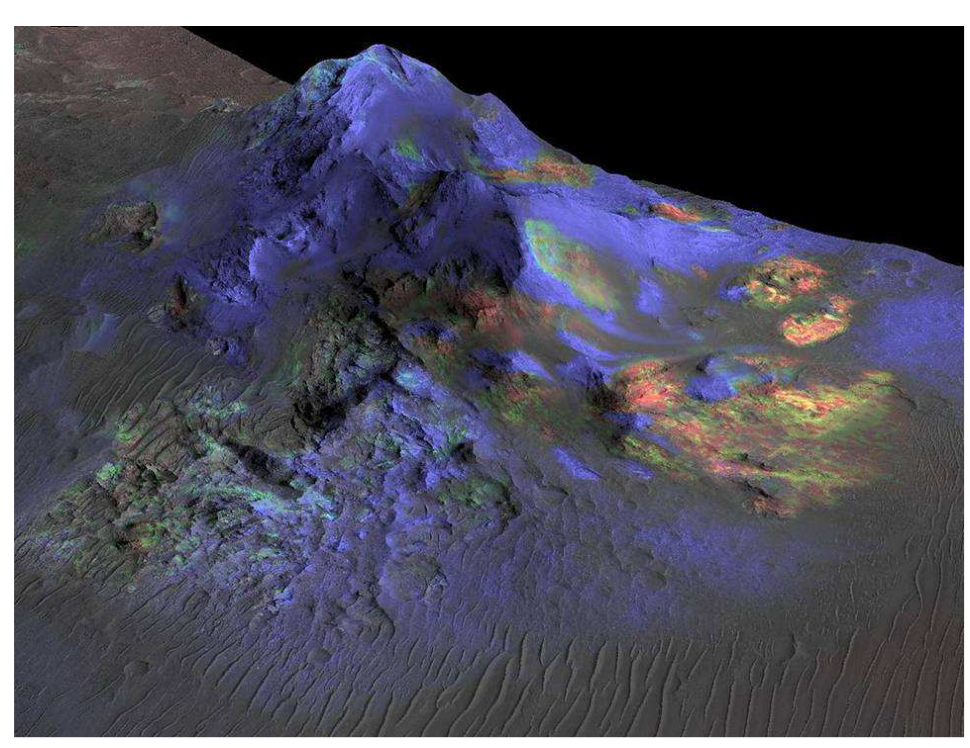

Fig. 3: Alga crater is thought to have deposits of impact glass that may have preserved ancient biosignatures if present during the impact

On December 9, 2013, NASA reported that, based on the Aeolis Palus curiosity, the Gale crater contained an old freshwater lake that could have been a very hospitable environment for microbial life. This confirmed that water circulates on Mars, that there are nutrients and, together with the previous discovery of a past magnetic field that protects the planet from cosmic and solar radiation, suggests that Mars could have environmental factors that sustain life.

However, the assessment of past habitats is not, in itself, evidence that Martian life has ever existed, but only that it could exist. If it was, it was probably a microbe in the liquid or sediment, either freely or in biofilm.

The possibility of living on Mars is a historical hypothesis formulated due to the proximity and similarities between this planet and Earth. The first serious investigations on this issue date back to the nineteenth century and continue today, especially with on-site exploration missions. Because, although "Martians" are a recurrent element in popular entertainment, such as film and comics, the presence of life on Mars, past or present, remains an open question.

If the first observation of the Martian polar traps dates back to the mid-seventeenth century, William Herschel noticed in the second half of the eighteenth century an alternate variation of their area in each seasons hemisphere.

Around 1850, astronomers have highlighted some similarities between Mars and Earth. The day is actually the same on both planets, the tilt of the axis of rotation that generates alternating seasons (although the Martian year is about twice as large as Earth's equivalent). These observations lead to the hypothesis that the dark areas visible on Mars correspond to the oceans, while lighter areas are continents. It is natural to assume that
Mars can host some life forms. William Whewell, a professor at Cambridge University in Trinity College, explains this theory in 1854 .

Mars, the theory of life multiplied at the end of the nineteenth century, following the observation of martial arts - which turned out to be just optical illusions. Thus, in 1895, American astronomer Percival Lowell published his book Mars, followed in 1906 by Mars and its channels, suggesting that these channels are the result of a dead civilization. This theory is addressed in particular by British writer H. G. Wells in his book "The Second World War" (1887), which describes an invasion of the earth by the beings on Mars and the escape of dehydration.

Mars, atmospheric spectroscopic analyzes begin in 1884. The American astronomer William Wallace Campbell shows that it contains neither oxygen nor water. In 1909, taking advantage of the shortest distance between Mars and Earth since 1877, astronomers point to the world's best telescopes on the red planet. These observations allow the completion of channel theory.

In 1965, the American spacecraft Mariner 4 was the first to fly Mars successfully, transmitting the first images of its surface. The photos reveal an arid planet without any sign of the river, ocean or life. However, they have large areas covered by craters, reflecting tectonic and meteorological inactivity for about four million years.

The probe also noticed the absence of a magnetosphere that would protect the planet from the cosmic rays of life. It manages to measure the atmospheric pressure of Mars: about $6 \mathrm{hPa}$ (versus 1013 $\mathrm{hPa}$ on Earth), which prohibits the existence of liquid water on the surface.

From Mariner 4, searching for life on Mars focused on finding simple, bacterial-like organisms instead of multicellular organisms for which the environment is too hostile. 
In the mid-1970s, the main purpose of the Viking program was to conduct experiments for the detection of microorganisms in Martian soil. Tests are designed to look for life forms similar to those found on Earth. Of the four experiments implemented, only the "Release Label" experiment (which corresponds to the detection of heterotrophic organisms) gives an apparently positive result, showing an increase in ${ }^{14} \mathrm{CO}_{2}$ production at the first exposure of Martian soil to a rich water and nutrient environment. But today scientists agree that these results are the result of non-biological processes and recall that the GC-MS experiment did not detect any organic molecules. However, there are many different interpretations of these experiences.

One of the "Release Label" designers, Gilbert Levin, believes his results are a definitive diagnosis of life on Mars. However, this is supported by many scientists who argue that the superoxide species that exist in the soil could have produced these effects without the presence of life. Therefore, a general consensus rejected the LR experiment data as a proof of life, because gas chromatograms and mass spectrometers designed to identify natural organic matter did not allow the detection of molecules. organic. The results of the Viking mission related to Viking are therefore considered by most inconclusive experts, the worst, the worst case, the invalid.

In 2007, at a seminar at the Geophysical Laboratory of the Carnegie Institution in Washington, Gilbert Levin's experiment was re-evaluated. Levin also claims that his original data is correct.

Ronald Paepe, an edaphologist (scientist), told the European Geological Congress that recent detection of filigree clays on Mars could result from pedogenic propagation on the planet. The interpretation of Mars de Paepe as active red erosion caused by water, vegetation and microbial activity.

A team of scientists from the Autonomous National University of Mexico, led by Rafael NavarroGonzalez, concluded that the material used by the Viking program to search for organic molecules may not be sensitive enough to detect low levels of organic compounds. Because of the simplicity of sample manipulation, TV-GC-MS is still considered the standard organic detection method for future martial missions. Navarro-González suggests that the design of future instruments for finding organic matter on Mars also includes other detection methods.

The affirmation of life on Mars in the form of a microbial called Gillevinia straata is based on old reinterpreted data as a sufficient proof of life, especially by professors Gilbert Levin, Rafael Navarro-Gonzalez and Ronald Paepe. The evidence supporting the existence of Gillevinia straata microorganisms is based on the data collected by the two Viking carpets for biosignal research. However, the analytical results were officially declared inconclusive by the scientific community.
In 2000, Gas and Mass Spectrometry (GC-MS) analysis investigated high molecular weight polycyclic aromatic hydrocarbons; NASA researchers have concluded that up to $75 \%$ of Nakhla organic matter can not be recent contamination of the soil.

Meteorite Shergotty is a 4-pound martian meteorite that fell on Earth in Shergotty, India on August 25, 1865 and was recovered by witnesses almost immediately.

This meteorite is relatively young, its formation was calculated only 165 million years ago, of volcanic origin. It is mainly composed of piroxen and is believed to have undergone a pre-ground water change for centuries. Some internal formations are remembered by biofilm remnants and their microbial communities. They work in search of the magnetite with phases of modification.

No other call from Mars because Viking sought out signs of life in the Martian regolith. Recent missions of NASA missions have focused on the presence of liquid water on Mars in the form of lakes in the distant past. Indeed, scientists have discovered hematite, a mineral that forms in the presence of water. Many scientists have long held this presence as almost obvious on the basis of various geological reliefs on the planet, but others have suggested different explanations, wind erosion, oxygen oceans, etc. Thus, the mission of Mars Exploration Rovers in 2004 was not present, but the evidence of liquid water on the surface of Mars in the ancient past of the planet.

In June 2000, evidence of a watercourse under the Martian surface in the form of rivers was found. Large liquid water reservoirs near the center of the planet could today be a habitat of life. However, in March 2006, astronomers announced the discovery of similar rivers on the Moon, which had never had liquid water on its surface. Astronomers suggest that the rivers could be the result of micrometeorite impact or carbon dioxide sublimation.

In March 2004, NASA announced that the Opportunity robot found evidence that Mars was a dwarf planet in the distant past. This raised the hope that the proof of life in the past could be found today on the planet.

In December 2006, NASA showed images made by Mars Global Surveyor, suggesting that water occasionally appeared on the surface of Mars. Images do not show dripping water. On the contrary, they showed changes in craters and sediment deposits, showing even stronger that the water did not pass through them until a few years ago and could do it again today. Some scientists are skeptical about the action of liquid water in the evolution of the surface seen by wells. They have said that other materials, such as sand or dust, can flow like a liquid and produce similar results.

A recent analysis by Mars, which uses data from orthoparticle spectrometry, suggests that the waters that previously existed on the surface of Mars would have been too saline to support most forms of relief. Tosca et al. (2008) found that Martian water in the studied localities had water activity, aw $\leq 0.78-0.86$ - a fatal level for most of the terrestrial life. Haloarchaea is however able 
to live in hypersaline solutions up to the saturation point (Tosca et al., 2008).

NASA Phoenix Mars Lander, which landed in Arctic Mars in May 2008, confirmed the presence of water ice near the surface. This was confirmed when the light materials exposed by drilling the probe arm vaporized and disappeared within 3-4 days. This was explained by ice under the surface, exposed by digging, which was sublimated by exposure to the atmosphere.

The methane traces of the atmosphere in March were discovered in 2003 and verified in 2004. The presence of methane is very interesting because this gas is unstable, indicating that there must be a source on the planet that maintains such a rate in the atmosphere. It is estimated that Mars has to produce 270 metric methane per year; the impact of the meteorite contributed only $0.8 \%$ to this production. Geological sources of methane are possible, such as serpentinitis, lack of volcanism, hydrothermal activity or hot spots is not favorable to geological methane. In 2012, cosmochemical researchers published an article in the journal Nature, which states that organic materials that can be contained in micromethorite produce methane in a significant amount under the action of ultraviolet. This methane production is stimulated by an increase in temperature, which corresponds to regions where there is exactly a higher concentration of methane, that is, the equatorial regions. The existence of life in the form of microorganisms, such as methanogens, is a possible source, but it is not yet proven. If there is a Martian methane that produces microscopic life, it is likely to be deep beneath the surface, where it is still hot enough to allow the existence of liquid water.

In February 2005, it was announced that the Fourier Planetary Spectrometer (PFS) on the Mars Express Orbiter of the European Space Agency detected traces of formaldehyde in the atmosphere of Mars. Vittorio Formisano, SFP director, speculated that formaldehyde could be the by-product of methane oxidation and, according to him, could prove that Mars is very geologically active or hosts microbial colonies. NASA researchers thought these preliminary results were worthy, but they also rejected them as a proof of life.

In May 2007, Spirit Rover interrupted a broken wheat field, revealing an area rich in silica $(90 \%)$. The feature is no different from the effect of a hot spring and/or water vapor that comes into contact with volcanic rocks. Scientists believe that this evidence of the living environment can be favorable to microbial life and their theory of possible origin is that silica was produced by interacting the soil with acid vapors produced by volcanic activity in the presence of water. Another could have been from a hot spring.

Black dwarfs, also known as Martian spiders, are features that can be seen first and foremost in the southern polar region (between 60 and $80^{\circ}$ latitude) of Mars, on or under polar ice. Stains were discovered on images made by Mars Global Surveyor between 1998 and 1999. Stains appear in the spring of March and disappear before the beginning of winter.

A theory of the possible biological origin of the stains was emitted by a Hungarian team, suggesting that the stains are colonies of photosynthetic martian microorganisms that live under the ice layer. When the sun returns to its pole at the beginning of spring, the light penetrates the ice, the microorganisms imagining that they are immediately heating their environment; a pocket of liquid water that instantly evaporates into Mars's thin air is trapped in ice.

When the ice layer fades, the micro-organisms are seen in gray. When it melts completely, it dries quickly and turns into black, surrounded by gray gold. Haloarchaea bacterium "salt-loving" was proposed to be used as a "model" to study these hypothetical extremophiles on Mars.

NASA's current theory is that stains are composed of basalt ash fragments or dark aggregates that would form sublimation residues. Although the European Space Agency (ESA) has not yet formulated a theory, it has indicated that the location and location of the places are in contradiction with a physical explanation.

In 1965, Mariner 4 discovered that Mars does not have a global magnetic field to protect the planet from the potentially lethal consequences of cosmic radiation and solar radiation, the observations made in the late 1990s by Mars Global Surveyor confirmed this finding. Scientists say the lack of magnetic protection has allowed the solar wind to cast much of Mars' atmosphere over billions of years.

In 2007, it was calculated that the cosmic radiation damage of DNA and RNA pushed life back to Mars at a depth of at least $7.5 \mathrm{~m}$. As a result, the best hope for a story about life on Mars is an environment that has not yet studied: basement.

The Phoenix mission was to land a lander in the northern polar region of Mars on May 25, 2008. It ran until November 10, 2008.

The two main objectives of the mission are to identify the regolith as a "habitable area" for microbial life and to study the geological history of martial waters on Tuesday.

LG is equipped with a $2.5 \mathrm{~m}$ robotic arm capable of digging $0.5 \mathrm{~m}$ over. An electrochemical experiment analyzes the ions present in the soil and determines in particular the amount and type of antioxidants present on Mars. Viking program data seem to indicate that the abundance of Martian oxidants may vary by latitude because Viking 2 found less oxidants than Viking 1 to the south. Phoenix landed further north than the two predecessors (Fig. 4). 


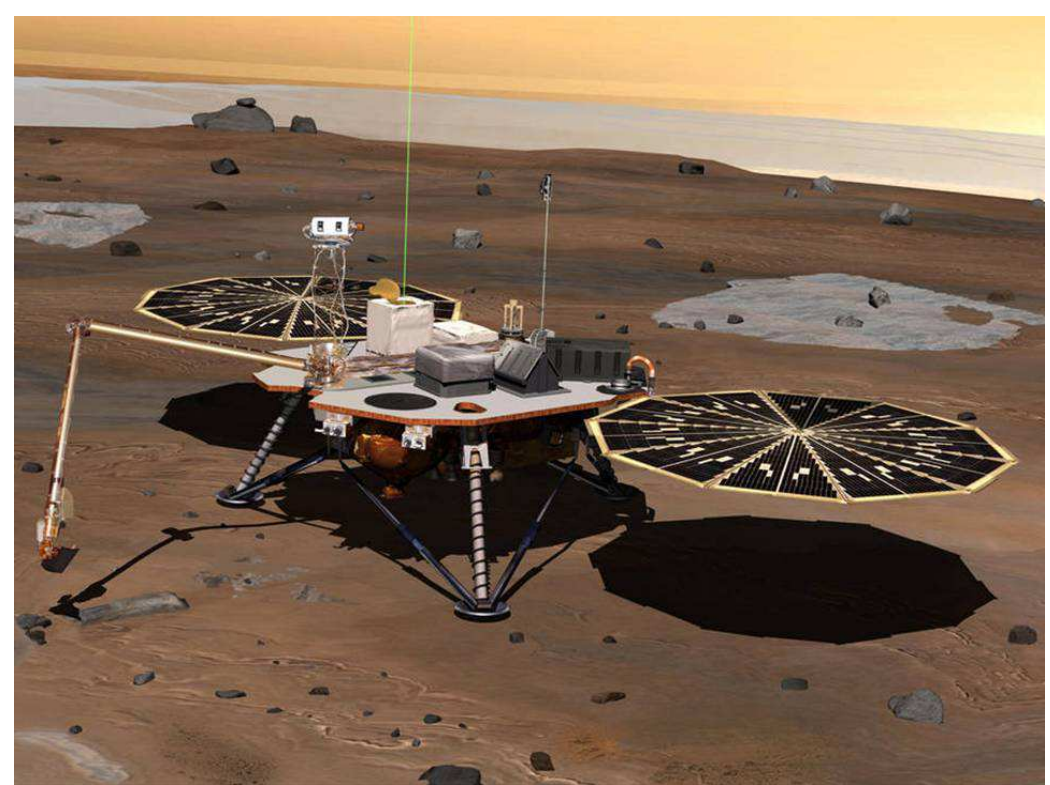

Fig. 4: Phoenix lander (2008)

Preliminary data from Phoenix indicates that Martian soil contains perchlorates and can not be as viable as the image. $\mathrm{PH}$ and salinity were considered benign from a biological point of view. Analyzers also indicate the presence of limited water and $\mathrm{CO}_{2}$.

Marine Science Laboratory (MSL) was launched on November 26, 2011 by NASA and released on August 6, 2012. It includes tools and experiments that address past or present conditions consistent with biological activity. NASA plans to launch the Astrobiology Field Laboratory in 2016 to answer the question of life on Mars. Task Force Analysis and Task Force are responsible for deciding what the mission experiences will be.

He pleaded for future sampling missions at different depths beneath the surface, where, according to some people, liquid water can be found and where microorganisms can survive cosmic radiation.

Mars Sample Return: The best life saving experience is examining a sample of Martian soil on Earth. However, the difficulty of securing and sustaining life during the Martian transit months remains to be resolved. Ensuring the environment and meeting unknown nutritional needs is still a challenge. If life forms are found dead in a test, it will be difficult to conclude if these organisms were alive at first.

March 2020: The expected mission in 2020, a planet will be sent to Mars to analyze the surface of Mars, thanks to the SuperCam project developed at Bordeaux Astrophysics Laboratory (LAB), which will be compared to Curiosity. Other instruments will be on board, such as a sample analyzer, a sample.
This photo of the Martian surface (Fig. 5-6), which contains snow-covered sand dunes, was made on May 21, 2017 with a HiRISE scanner from GODMOTHER's Marbi Reconnaissance Orbiter.

When photographed, it was the spring of the northern hemisphere of the red plant. In winter, in March, the sand dunes were completely covered by snow and ice. Unlike Earth, the snow and ice on Mars are made up of carbon dioxide and not water and is also called "dry ice."

When sunlight begins to warm the Martian surface in spring, the ice on the smooth surface of the dunes breaks and released carbon dioxide pushes the sand and darker dust into the surface of the dune, producing "beautiful" orbits.

On the dull side of the dune, dry ice lasts longer, being shaded by the edges of the dunes.

It is late winter in the southern hemisphere of Mars and these dunes are just getting enough sunlight to start defrosting their seasonal cover of carbon dioxide.

Spots form where pressurized carbon dioxide gas escapes to the surface.

This image was taken on March 27, 2016, at 15:31 local Mars time by the High Resolution Imaging Science Experiment (HiRISE) camera on NASA's Mars Reconnaissance Orbiter (Fig. 6), (Mcewen, 2016).

This paper attempts to propose such concepts and from respect to our wonderful pilots, but also with the conviction that humanity period in galactic and universal expansion has already begun (Aversa et al., 2016a; 2016b; 2016c; 2016d; 2017a; 2017b; 2017c; 2017d; 2017e; Cataldo, 2006; Mirsayar et al., 2017; Petrescu and Petrescu, 1995a; 1995b; 1997a; 1997b; 1997c; 2000a; 
2000b; 2002a; 2002b; 2003; 2005a; 2005b; 2005c; 2005d; 2005e, 2016a; 2016b; 2016c; 2016d; 2016e; 2013; 2012a; 2012b; 2011; Petrescu et al., 2009; 2016a; 2016b; 2016c; 2016d; 2016e; 2017a; 2017b; 2017c; 2017d; 2017e; 2017f; 2017g; 2017h; 2017i; 2017j; 2017k; 2017l; 2017m; 2017n; 2017o; 2017p; 2017q; 2017r; 2017s; 2017t; 2017u; 2017v; 2017w; 2017x; 2017x; 2017y; 2017z; 2017aa; 2017ab; 2017ac; 2017ad; 2017ae; Petrescu and Calautit, 2016a; 2016b; Crickmore, 1997; Donald, 2003; Droste, 1915;
Fernandez et al., 2005; Finkelstein, 1958; Fonod et al., 2015; Goddard, 1916; Goodall, 2002; Gorder, 2015; Graham, 2002; Gruener, 2006; Gunston, 2010; Hewish, 1970; Jenkins, 2001; Kaufman, 1959; Laming, 2000; Landis and Jenkins, 2005; Larson, 2015; Lu et al., 2015; 2016; Michell, 1784; Murray et al., 2010; Norris, 2010; Oberth, 1955; Oppenheimer and Volkoff, 1939; Palumbo et al., 2012; Patre and Joshi, 2011; Sevil and Dogan, 2015; Sherson et al., 2006; Ward, 2010; Williams, 1995).

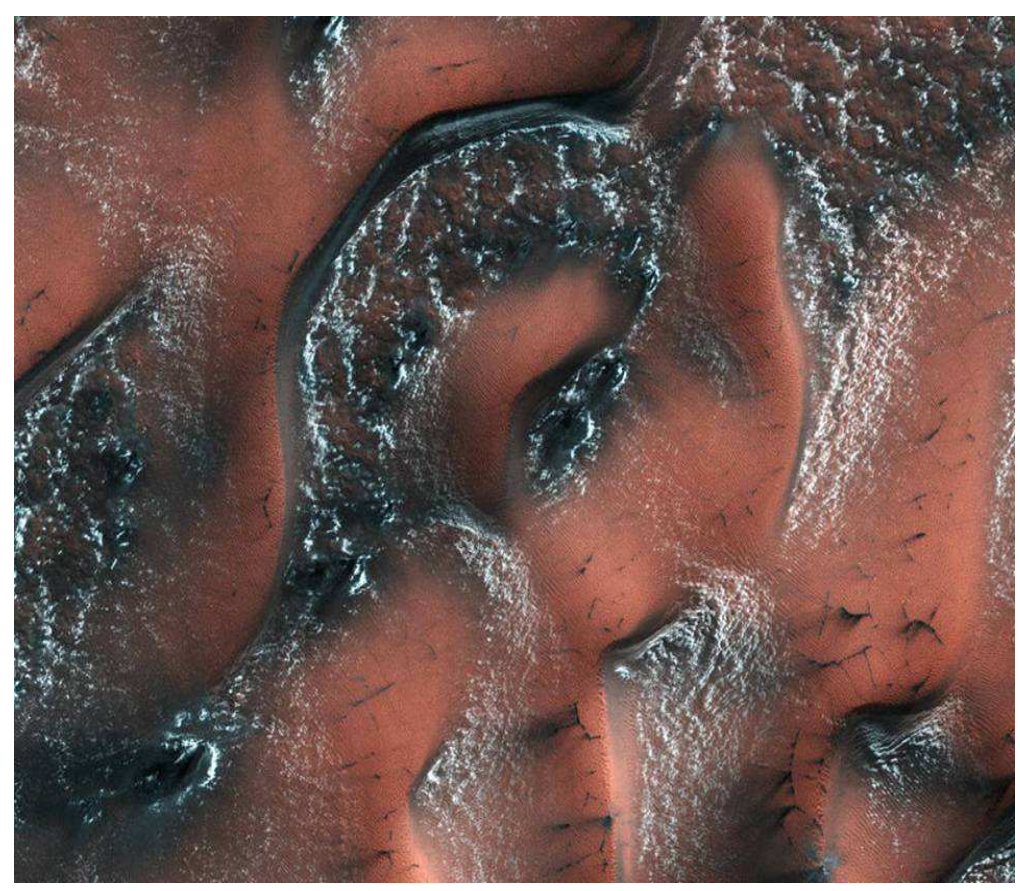

Fig. 5: A world of snowy dunes on Mars

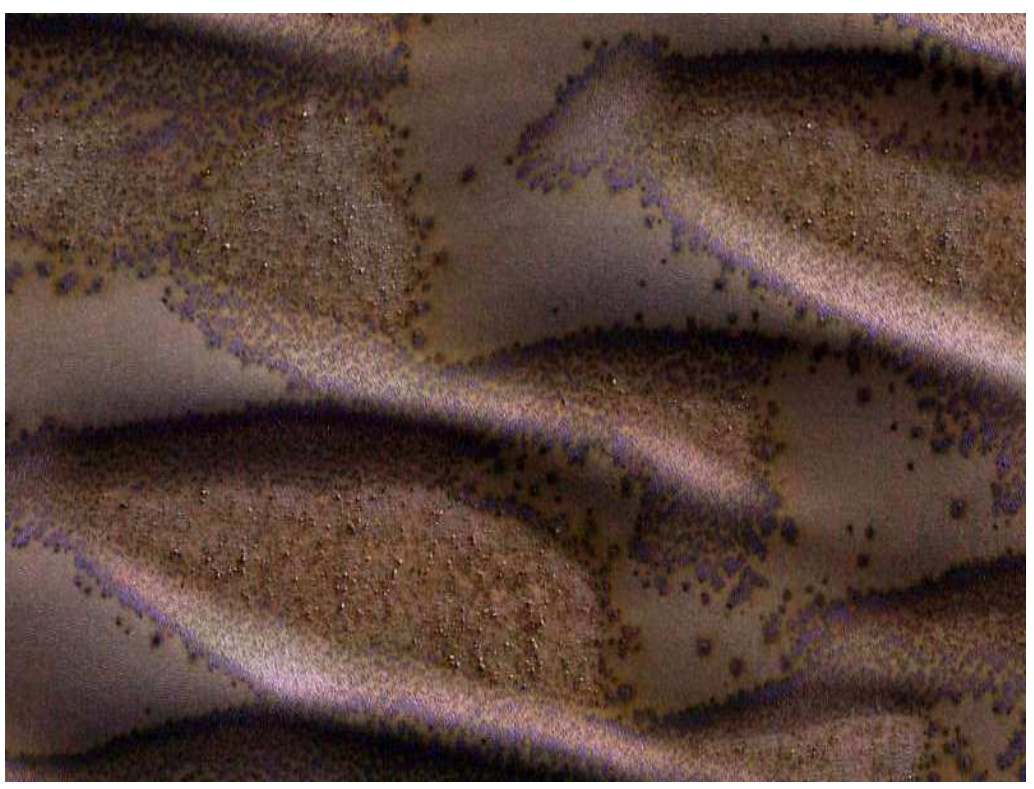

Fig. 6: Frosted dunes on Mars 


\section{Results and Discussion}

In the SXSW 2018 event, Elon Musk shared with the public some ideas about the functional structure of a Martian colony. "Most likely, the form of government will be a direct democracy, where people can vote directly on what they are interested in, instead of relying on representatives."

The colony imagined by Elon Musk could become reality sooner than we imagined the majority. Musk can already be proud of the success of Falcon Heavy, which sent Starman to space. The entrepreneur has already revealed some of the plans for a human colony. In 2017, he says he is going to provide the necessary funds for such a project and the next logical step is to find a system of government.

It discusses the early US, where the lack of technology has led to the creation of representative democracy. Without a means of instant communication, no postal services, no written and read knowledge of people, direct democracy could not have been a solution for the development of the States.

Future Marxian colonies will have access to state-ofthe-art technologies, but their beginnings on the Red Planet will be quite difficult, though. Muskcomparates these future colonies with the first colonies in the Western Hemisphere and does not forget to mention that "some people will probably die."

There are a lot of major dangers for the people who will live on Mars, so it's good that the laws are simple (Elon Musk).

The human colonization of Mars is the centerpiece of speculation as well as of a serious scientific study because surface conditions and the existence of Mars water undoubtedly make the planet the most hospitable of the solar system, planet earth. The moon was proposed as the first location of human colonization due to its proximity, but Mars has a thin atmosphere, offering a potential capacity to host human life and other organic life forms. Both the Moon and Mars, as potential colonization locations, have the disadvantages of high costs and risks associated with the flight of technological equipment under gravity, which makes asteroids another option for rapidly expanding people into the solar system.

The surface of Mars is about the same size as the land surface on Earth. The ice from the South Pole stretched across the planet would form a layer of 12 meters thick. It may be that Mars has gone through the same geological and hydrological processes as Terra and could, therefore, contain minerals. There is already equipment that could extract the resources (water, air) from the earth and the Martian atmosphere on the spot. The interest in colonizing this planet is due to the evidence that life has existed and may still exist on Mars.

Unfortunately, the atmosphere is very poor $(0.8 \%$ of the sea-level atmosphere on Earth) and the climate is much colder. Gravity is only a third of Earth's, but it is not known if it could sustain human beings in the long run. Because the atmosphere is weak and Mars lacks a strong magnetic field, the radiation is intense to the surface, requiring anti-radiation protection.

Terraforming Mars would make life outside possible pressurized buildings; there is discussion whether or not it can be achieved. Mars is considered by specialists to be the first on terraforming list. This planet lacks three important elements: Dense atmosphere, extended magnetosphere and heat.

The atmosphere of the planet is reduced, requiring a dense one containing greenhouse gases, such as carbon dioxide. With the help of the gases, the solar heat is captured in the atmosphere, thus raising the planet's temperature. A higher temperature amplifies the effects of greenhouse gases by releasing the gases from the soil, the two supplying each other. Greenhouse gases can be produced on Mars if plants and factories that pollute a lot are built there, this planet having all the materials needed for the industry. The products of these factories can be used to build human settlements on the planet.

The warming of the planet can be done by two ways: Using greenhouse gases, using several giant mirrors that redirect sunlight to the planet, activating the planet's core by impact or impacting an asteroid or comet large enough to produce enough heat and gas emissions.

Immediately after the warming of the planet, water will also appear. Water is already on Mars in solid state, the planet has ice caps and a frozen lake. It is also believed that at a certain depth, where it is warmer, water can be found even in the liquid state.

The water on Mars, experts say, is most likely to be toxic, with a very high salt level, salt being found in many places on this planet. Still, there are very salty waters on Earth, so we can use the creatures in our waters to populate the Martian waters. These creatures will produce oxygen and other essential elements, some bacteria probably can clean it out of salt.

Like the atmosphere, the magnetosphere is very small, covering about $40 \%$ of the planet. In the distant past of Mars's history, it had an extended magnetosphere and the planet was generally more Earth-like. This is proven by the meteorite ALH 84001, found in Antarctica on December 27, 1984, by a team of meteorite seekers. This rock on Mars fell 11 million years ago. After being examined it was found to be magnetized, some traces of magnetization dating from the time when both Mars and Terra were bombarded with meteorites. Like this rock, many fell, all coming from Mars and being magnetized. The first was found in Egypt in 1911.

After officially deciding that Mars had an extended magnetosphere and that it was almost the same as Terra, the hypothesis was still in the debate that Terra's life had come from Mars, proving that microorganisms can 
survive a journey aboard a meteorite, sheltering inside, where they are protected, the temperature barely rising a few degrees, some of them resisting the impact, after which they can evolve and populate the planet. At present, Mars arrives on Terra with a ton of material, possibly much more in the past, making it possible.

Building colonies would primarily require basic elements for survival: Water, food, raw materials, vital support, energy, communications, transport, artificial gravity and anti-radiation protection.

Colonies on the Moon, Mars, or on some asteroids could extract local resources. The moon is lacking in nitrogen, but it has vast reserves of hydrogen in the form of frozen water under the crust of dark craters, but it also has oxygen, silicon and metals like iron or aluminum. Sending materials on Earth would be expensive, so they could be sent from the moon, NEO (Near Earth Object = asteroids, comets) or Phobos and Deimos, the moons of Mars. Many NEOs contain oxygen, hydrogen, metals and carbon and some and nitrogen. Further, it is believed that Jupiter's asteroids would have frozen water and volatile elements.

Solar energy in orbit is abundant and is still used by satellites today. There is no night in space, no clouds or atmosphere to block the sunlight, so this energy is available at any distance from the sun. The moon has nights lasting for 2 weeks on Earth and Mars has night and dust and is farther away from the Sun, reducing the available solar energy, making it more attractive to use nuclear energy. Alternatively, solar energy could be transmitted to these bodies by using satellites. For both methods, however, in airless environments such as the Moon and space, but also in Mars's mild atmosphere, large spaces would be needed for the radiation emanating from the heat generated.

Orbit transport is usually the limiting factor in space travel. A solution is given by the supersonic ship under development at NASA. Other alternatives would be the construction of space lifts and electromagnetic catapults ("mass driver"). The transport of at least materials to and between colonies is necessary, but expensive by using resources on Earth. Potential solutions could be thermonuclear propulsion, magnetic and solar wafers, solarthermal missiles or ion drive. On the Moon you could use the space lifts, but also the catapults.

Compared to other requirements, orbital and monthly communications are mild. Much of terrestrial communications is already using satellites. But as the colonies deviate from Terra everything becomes more complicated. Transmissions from and to Mars suffer from significant delays due to the speed of light and distances (delays vary between 7 and $44 \mathrm{~min}$ ), making direct communications impractical. However, the use of emails or voice messages should not be a problem.

In space settlements, a closed ecological system must recycle and import everything without yielding. The requirements for this would be:
- Organisms and habitat to be totally isolated from the outside environment (artificial biospheres)

- Changing the environment to be life-friendly (terraforming)

- Changing organisms to be compatible with the environment (genetic engineering, cyborgi)

Also, $97-99 \%$ of the solar energy given to plants is heat dissipated to avoid overheating.

Cosmic rays and solar eruptions create lethal radiation in space. In Earth's orbit, Van Allen belts make life outside the difficult atmosphere. To protect life, the settlements must be surrounded by sufficient mass to absorb the radiation. It takes 5-10 tons of material per square meter for that. Residues from planetary soil and asteroids would be a variant, but would make the maneuvering of a ship more difficult.

The idea of space colonization is primarily based on spacecraft capable of transporting people and resources between planets and other celestial bodies. Hypothetically, the spacecraft proposed by SF as well as by scientists are:

- Ship generation: Underwater speed; interstellar journeys for decades or centuries; the crew goes through generations to the end of the journey, so it is not to be expected that someone in the original crew will reach their destination (in average life) - but only their descendants

- The hibernating ship: Most crew spend hibernating or suspended animation so that most of the original crew will arrive at their destination

- Embryo-carying Interstellar Ship (EIS): Is a much smaller vessel than the first two; transported human embryos and/or frozen or latent DNA

- Fusion/Nuclear Fission Vessel: Speed up to $10 \%$ of the speed of light, allowing a single journey to the destination during a man's life (without returning to Earth)

Orion: Uses nuclear propulsion (Freeman Dyson Orion Project), more specifically the nuclear explosion.

The laser ship: Propulsion based on the use of a form of light concentration for solar flares or other types of ships, with speeds comparable to those obtained from nuclear fusion; it still requires other propulsion methods to stop at the destination (most likely a hybrid ship: With solar clutches for acceleration, fusion for deceleration).

Some reasons to begin space colonization by humans:

- The spread of life and beauty in the Universe

- Ensuring the survival of the human species

- Profit from asteroid mining, solar energy and space production 
- Saving the Earth's environment by moving people and industry into space

- Rare resources, such as natural gas from gas giants

The population on Earth is steadily increasing, while resources and capacity do not. The opening of space would exceed these limits, however, extrapolations show that the population will stagnate by 2070 . Even if humanity succeeds in avoiding the destruction of the Earth through wars, plagues, pollution, global warming and cooling or even meteor impacts, Terra will inevitably become uninhabitable because of the warming of the Sun as it ages. If humanity does not have permanent settlements until one of these disasters happens, it may even disappear.

Although initially the trips will be very expensive, especially due to meeting the needs of the colonies, as soon as they are met, additional productions can be used to expand the initial infrastructure or send back to Earth for the early investment. Also, new high-value goods can be discovered: Precious metals and stones, energy sources and fuel or pharmaceuticals.

All these colonies and space explorations must be free of national interests and the Earth become unitary, without political boundaries. Already, international collaborations in space have demonstrated their value in the unifying and cooperative effort.

At the moment, we can only talk about it and dream about it. But over a relatively short period of time, we will get there - on the Red Planet - and over the next few decades, we will have the technology to make Mars a more habitable planet than now, expanding the boundaries of human civilization beyond its native planet. But what does this transformation mean? And what will we do if we find that there are life forms on Mars? Such important questions arise when we talk about the colonization of the Martian world and we will need to think well and give some answers before embarking on the Martian adventure. Here, as a starting point, the expert opinions of an expert, NASA astrobiologist Chris McKay, who will guide us in making scenarios about the Great Martian Preface.

In a recently published article, McKay, an astrobiology specialist at the NASA Ames Research Center, discusses the meanings of the various terms used to refer to the transformation of Mars through human intervention and the methods by which such spectacular transformation could be made.

One of the terms spoken is terraformation - a word found in SF literature and cinema, designating a radical transformation of another planet to make it similar to Earth. The purpose of such an intervention is obvious: Creating a land-like environment that allows earthly people to survive.

But terraforming means that we do not take into account what might exist on Mars as life forms. Of course, at the moment we do not know that there is anything alive on the Red Planet, but in-depth research has just begun.

In addition to terraformation, there is theoretically the possibility of a "restoration" of the planet to resuscitate the biodiversity that might still exist there as much as it may be - perhaps microbial communities still uncovered by us, surviving in very restricted habitats, perhaps in the form of very resilient, still viable spores that could be reactivated if the conditions on Mars had ever become less harsh.

McKay (1991) proposed to use a less geocentric term than the terraformation: planetary ecosynthesis (which sounds as impressive as it may be) to designate the process by which it could be created at the surface of the Red Planet stable and diverse biosphere.

Would it be the creation of such a larger and more valuable planet for us than the preservation of the Martian world as it is now, when it offers the opportunity of absolutely unique studies?

If we are playing with ideas, developing a first scenario, let us say that economic necessity would force us to make the decision to expand, to occupy another planet. How would the planetary ecosynthesis that would make the dry and frozen Mars a welcoming planet for man, blue and green like Terra, with water and vegetation? Would it be possible? Let's see what the astrobiologist wizard guides us in drawing up this scenario.

The first step would be to modify the Martian atmosphere so that the planet becomes more humid and warmer. Mars had a much wider past, 4 billion years ago there would have been even an ocean and the researchers agree that there is still water captive in the structure of the rocks that make up the planet and in the form of ice. On the poles of the planet lie two large ice caps, formed mostly of frozen water. This ice must be melted to have water on Mars; this process - the Great Melting, as McKay calls it - would take several centuries.

For the ice to melt, temperatures need to be much higher than today. How could the warming of the planet be achieved? Applying what we know about Earth and its atmosphere: so-called greenhouse gases contribute to heat retention. Large greenhouse gases such as Chlorofluorocarbons (CFCs) could be introduced on Mars that would warm the Red Planet to some extent and trigger other processes that would further contribute to heating.

When I wrote that the ice shields on the Martian poles are formed mostly of frozen water, I bet you wondered what else could have been formed: well, they are composed - on the surface, more exactly - frozen carbon dioxide (carbon ice), which is formed by the fact that the temperatures are very low (carbon dioxide freezes at temperatures lower than minus 78.5 degrees Celsius).

Above this temperature, carbon dioxide would sublime, that is, it would pass from the solid state 
(carbon ice) directly into the gaseous state, the state in which it is found in the terrestrial atmosphere. Carbon dioxide is also a greenhouse gas, which would further lead to the process of heating, melting frozen water and forming a more dense atmosphere. And, at last, there would be rivers and rivers flowing back on Mars, like billions of years ago.

But if the Great Melting took only a few centuries, it would be necessary, according to astrobiologist predictions, for about 100,000 years for genetically modified photosynthetic life forms to release enough oxygen to bring its concentration to the Martian atmosphere at the level on Terrra.

Oxygen could form an ozone layer (which is a compound with a molecule of 3 oxygen atoms, unlike the usual oxygen form, the one we breathe and has a 2 molecule molecule) that would protect the planet the excess of ultraviolet radiation - as is the case with Terra and the anti-UV defense could be amplified by discharging into the Martian atmosphere, every year, approx. 10 million tons of carbon oxidesulfide, a gas with an unpleasant sulphurous smell and which is naturally emitted by volcanoes on Earth (fortunately, it is found in the earth's atmosphere in too small concentrations to bother us).

We are, therefore, talking about a process based on photosynthesis, which would be the biological scenario through which the Martian atmosphere could be enriched with oxygen, reducing the amount of carbon dioxide.

Alternatively, if non-biological technologies could be set up to do the same, then Mars could have a breathable atmosphere in a shorter time - maybe 10,000 years.

The first familiar ecosystems that would appear would be tundra - tundra alpina and polar tundra - with lichens, mosses and fine small plants; then, gradually, even higher forms of vegetal life would appear, even trees, forests ...

There could then be introduced invertebrate animals such as earthworms, which have a huge role on the Earth, improving the structure of the soil - and insects: Pollinating insects would help to increase plant diversity.

Well, if we discover microorganisms on Red Planet, then the strategy will have to be totally different: We should try to restore the planet, to rebuild its ecology as it was 4 billion years ago. We should avoid introducing terrestrial life forms of any kind and let us give the planet water and dense atmosphere to prime the evolution of its forms of life. And then we'll wait and see what's going on. We will witness something extraordinary: The evolution of life on a planet other than ours and we will be able to make comparisons and studies that we can not even imagine in detail.

"To restore the global diversity of life on Mars would be the best option for Mars," McKay said. "However, if Mars life is genetically similar to Earth's, or if there is no life on Mars that we can resurrect, then a Mars planet striving for terrestrial life forms is the second option in the order of preferences."

Not everyone will agree with Chris McKay, but I think we will all agree with Ray Villard, the author of the article, that it is a decision that ultimately mankind will have to assume and which will face the first "major alien dilemma" of our existence. As our most advanced species in the Solar System, are we entitled, asks the author, to decide the destiny of other worlds?

Every year, we are approaching the moment when we are technologically capable of undertaking these actions that seem today to be quoted in a novel of anticipation: To give a planet water and air, to give it - or to make it life, let us We make it and transform it to our taste ...

There is something great and scary at the same time, a kind of demiurgic action full of consequences that is hard to suspect and for which we will have to take responsibility with good and evil when deciding to start adventure.

The present can be characterized by an extraordinary rhythm of conquests of technology, science and social culture; this true "explosion of scientific knowledge" starts from the microcosm, benefits from the performance of computers, nuclear power, astrophysics and astronauts and extends through the penetration of "the minds of the mind" (but also with devices that are ever more stunted) into the mysteries of the universe. Millennium Endeavor puts immense efforts to humanize the cosmos, provide energy and food resources for seven billion earthquakes, develop the future or genetic engineering projects of the future or genetic engineering heliocentre, subject nuclear fusion and send automated ships to the limits of the solar system or to eradicate some diseases such as AIDS or cancer ... Impressive by their vastness and high humanism, these programs are based on a long line of achievements, most of them achieved over the last decades: Penetration into living cell life and genetic technology provide the necessary food resources for humanity and stop some destructive diseases; after seizing Selena and depositing clever robots on Mars and Venus, "homo cosmicus" sent its automatic emissaries to the limits of the solar system and even further; nuclear energy is already a generalized reality and unconventional sources make permanent progress; after they have "conquered" the industry, robots driven by supercomputers are preparing to ... migrate into the cosmos; large scale planetary programs such as knowledge have been initiated ocean, rescue of ships in danger, eradication of the wilderness and poverty of the third world, extinction of forest fires, etc.; many specialized satellites transmit television programs directly from the cosmos, etc. The current technological civilization has built a specific path based on the technical and scientific conquests of the twentieth century, evolving on cybernetic-computer-related coordinates; however, technology remains an instrument to meet certain requirements, to meet the needs of 
mankind. Thus, the development of nuclear technology has been encouraged by "hunger for energy"; cosmic flights - the requirement for better knowledge of the Earth and the exploitation of the cosmos; genetic engineering - the need to provide normal food supplies on Earth; computers - the need to establish (and quickly!) the chances of achieving the ambitious plans of the second millennium ... This is why it is a duty of honor to be an honest scientist and aware of his purpose to undertake the most energetic actions in order to prevent a catastrophic nuclear conflict on the "wonderful blue planet" that is the Earth (Sagan, 1989).

Elon Musk announced at the International Astronautical Congress (IAC) in Adelaide some important changes to his plan to colonize Mars. The new updates focus on the transport vehicle called the Interplanetary Transport System that would ship the first 100-200 people to the Red Planet (Musk Elon).

SpaceX plans to ship at least two cargo spacecraft on Mars in 2022 to "confirm the existence of water resources and identify potential hazards" and also "provide the necessary infrastructure for future flights."

Water resources are essential for producing a new type of fuel on Mars, which is necessary for the engines of transport vessels that have to return to Earth.

In 2024, Elon Musk plans four spacecraft, two of which will carry 100 people each and two will be destined for freight (cargo), to commence a three-month trip to Mars. In this space mission, the necessary materials, solar panels and equipment for mining will be transported on Mars to build a special fuel storage facility by extracting and refining water and carbon dioxide.

The Martian base will initially be formed from a single ITS interplanetary transport vessel. Then from several ITS ships, after which will form a small town and later a larger city. Elon Musk asserts that Marathon's "terraforming" phase continues to make it "a good place to live" as shown in the picture below (Fig. 7).
The initial plan of colonization of the planet Mars was originally presented in 2016 by Elon Musk at the International Astronautical Congress in Guadalajara, Mexico, later detailed in specialized journals.

Meanwhile, Lockheed Martin also revealed details of Mars Base Camp base concept within the IAC.

Lockheed Martin plans to send people to Mars within a decade. To this end, the company coordinates its efforts with NASA, which develops the Deep Space Gateway space orbital space station and a spacecraft that can land on the surface of Mars.

Elon Musk's new plan now provides for his ships to reach Mars in 2022, as Elon Musk announced in Adelaide. People will take this trip to the space shuttle module of BFR (Big Falcon Rocket).

SpaceX aims to reduce the cost of mission by improving the "Automated Rendevous and Docking" system. BFR will consume up to 150 tons of propellant to reach a low Earth Orbit, requiring a 150-tonne refueling in space to reach "Mars".

"If the propeller tank is reusable and we can realign the propulsion, then the costs will be reduced," said Elon Musk, who added that reducing mission costs to $\$$ 100,000 for an astronaut is absolutely necessary.

Elon Musk also said that next year we will be able to see how the spacecraft Dragon 2, developed by SpaceX, will connect to the International Space Station without any human intervention.

Funding needed to develop BFR will come from the launch of satellites and the services SpaceX offers to the International Space Station. Elon Musk intends BFR to serve the International Space Station in the future.

The pressurized cabin of the BFR spacecraft will have a larger volume than that of an A380, which will allow the construction of 40 cabins and a common area. Elon Musk said that for a trip that will take between 3 and 6 months, obviously cabins are required and not just simple places to travel (Musk Elon).

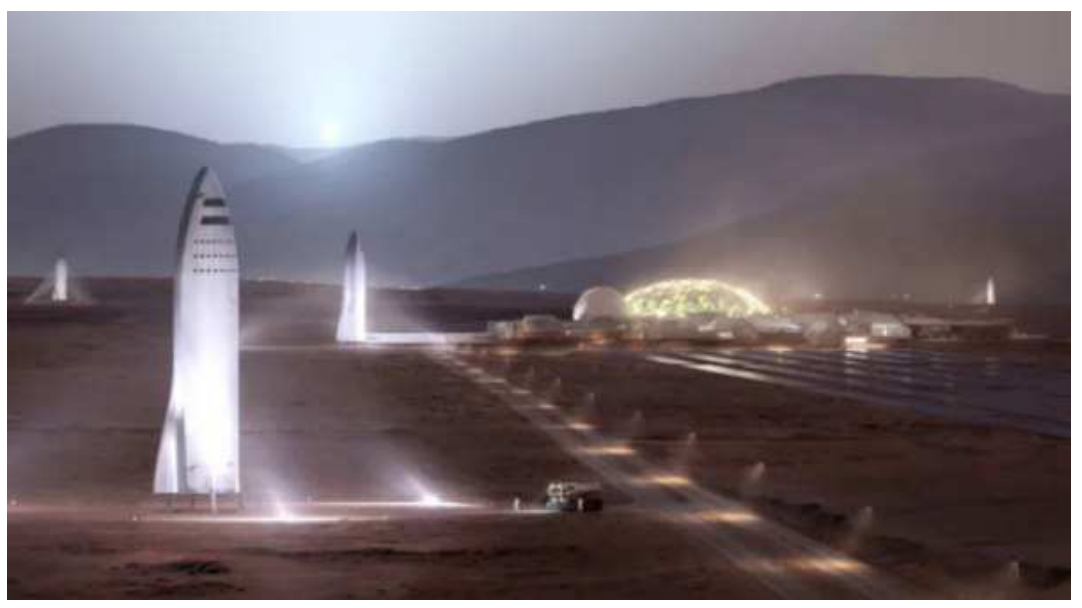

Fig. 7: Elon Musk asserts that Marathon's "terraforming" phase continues to make it "a good place to live" 
In a cabin you can travel 5-6 people, but the ideal number would be 2-3, which means that onboard the BFR will be about 100 people per flight.

The BFR spacecraft will also include sunblocks, storage, a kitchen and even entertainment areas.

Importantly, the BFR will have two landing motors as a precaution if one of them fails (Farquhar, 2017).

\section{Conclusion}

It can be said that the moment of the beginning of the colonization of the planet Mars by mankind is very close. Such a long-awaited and desirable event will certainly represent a major objective of our planet and humanity. Anything as difficult as any is harder until it starts. Then it will go on its own, with success and with possible falls, but it is important that it will finally start.

\section{Acknowledgement}

This text was acknowledged and appreciated by Dr. Veturia CHIROIU Honorific member of Technical Sciences Academy of Romania (ASTR) PhD supervisor in Mechanical Engineering.

\section{Funding Information}

Research contract: Contract number 36-5-4D/1986 from 24IV1985, beneficiary CNST RO (Romanian National Center for Science and Technology) Improving dynamic mechanisms internal combustion engines. All these matters are copyrighted. Copyrights: 548cgiywDssin, from: 22-04-2010, 08:48:48.

\section{Ethics}

This article is original and contains unpublished material. Authors declare that are not ethical issues and no conflict of interest that may arise after the publication of this manuscript.

\section{References}

Aversa, R., F.I.T. Petrescu, R.V. Petrescu and A. Apicella, 2016a. Biomimetic FEA bone modeling for customized hybrid biological prostheses development. Am. J. Applied Sci., 13: 1060-1067. DOI: 10.3844/ajassp.2016.1060.1067

Aversa, R., D. Parcesepe, R.V. Petrescu, G. Chen and F.I.T. Petrescu et al., 2016b. Glassy amorphous metal injection molded induced morphological defects. Am. J. Applied Sci., 13: 1476-1482. DOI: 10.3844 ajassp.2016.1476.1482

Aversa, R., R.V. Petrescu, F.I.T. Petrescu and A. Apicella, 2016c. Smart-factory: Optimization and process control of composite centrifuged pipes. Am. J. Applied Sci., 13: 1330-1341.

DOI: 10.3844 /ajassp.2016.1330.1341
Aversa, R., F. Tamburrino, R.V. Petrescu, F.I.T. Petrescu and M. Artur et al., $2016 \mathrm{~d}$. Biomechanically inspired shape memory effect machines driven by muscle like acting NiTi alloys. Am. J. Applied Sci., 13: 1264-1271. DOI: 10.3844/ajassp.2016.1264.1271

Aversa, R., R.V. Petrescu, A. Apicella and F.I.T. Petrescu, 2017a. Nano-diamond hybrid materials for structural biomedical application. Am. J. Biochem. Biotechnol., 13: 34-41. DOI: 10.3844/ajbbsp.2017.34.41

Aversa, R., R.V. Petrescu, B. Akash, R.B. Bucinell and J.M. Corchado et al., 2017b. Kinematics and forces to a new model forging manipulator. Am. J. Applied Sci., 14: 60-80. DOI: 10.3844/ajassp.2017.60.80

Aversa, R., R.V. Petrescu, A. Apicella, F.I.T. Petrescu and J.K. Calautit et al., 2017c. Something about the $\mathrm{V}$ engines design. Am. J. Applied Sci., 14: 34-52. DOI: 10.3844/ajassp.2017.34.52

Aversa, R., D. Parcesepe, R.V. Petrescu, F. Berto and G. Chen et al., 2017d. Processability of bulk metallic glasses. Am. J. Applied Sci., 14: 294-301. DOI: 10.3844/ajassp.2017.294.301

Aversa, R., R.V. Petrescu, A. Apicella and F.I.T. Petrescu, 2017e. Modern transportation and photovoltaic energy for urban ecotourism. Transylvanian Rev. Administrative Sci., 13: 5-20. DOI: $10.24193 /$ tras.SI2017.1

Bujor, O., 2016. On Mars there was water billions of years before scientists considered the phenomenon possible.

Cataldo, R., 2006. Overview of planetary power system options for education. ITEA Human Exploration Project Authors, Glenn Research Center, Brooke Park, OH.

Crickmore, P.F., 1997. Lockheed's blackbirds-A-12, YF-12 and SR-71A. Wings Fame, 8: 30-93.

Donald, D., 2003. Lockheed's blackbirds: A-12, YF-12 and SR-71. Black Jets. AIRtime.

Droste, J., 1915. On the field of a single centre in Einstein's theory of gravitation. Koninklijke Nederlandsche Akademie van Wetenschappen Proc., 17: 998-1011.

Farquhar, P., 29 SEP 2017. Here's Elon Musk's spectacular plan for colonising Mars. Sci. Alert.

Fernandez, V., L.F. Penin, L.F. Araujo, J. and A. Caramagno, 2005. Modeling and FDI specification of a RLV re-entry for Robust estimation of sensor and actuator Faults. Proceedings of the Guidance, Navigation and Control Conference and Exhibit, Aug. 15-18, AIAA San Francisco. DOI: $10.2514 / 6.2005-6254$

Finkelstein, D., 1958. Past-future asymmetry of the gravitational field of a point particle. Phys. Rev., 110: 965-967. 
Fonod, R., D. Henry, C. Charbonnel and E. Bornschlegl, 2015. Position and attitude model-based thruster fault diagnosis: A comparison study. J. Guidance, Control, Dynam., 38: 1012-1026. DOI: 10.2514/1.G000309

Goddard, 1916. Rocket apparatus patent. December 15, 1916, Goddard, Smithsonian Institution Archives.

Goodall, J., 2002. Lockheed's SR-71 'Blackbird' Family: A-12, F-12, M-21, D-21, SR-71. 1st Edn., Midland Publishing, Hinckley, UK, ISBN-10: 1857801385, pp: 128.

Gorder, P.F., 2015. What's on the surface of a black hole?: Not a "firewall"- and the nature of the universe depends on it, physicist explains. The Ohio State University, USA.

Graham, R.H., 2002. SR-71 Blackbird: Stories, Tales and Legends. 1st Edn., Zenith Imprint, North Branch, Minnesota, ISBN-10: 1610607503.

Gruener, J.E., 2006. Lunar exploration (Presentation to ITEA Human Exploration Project Authors, November 2006, at Johnson Space Center). Houston, TX.

Gunston, B., 2010. Airbus: The Complete Story. Haynes Publishing UK, Sparkford, ISBN-10: 1844255859, pp: 288.

Hewish, A., 1970. Pulsars. Ann. Rev. Astronomy Astrophys., 8: 265-296.

Jenkins, D.R., 2001. Lockheed Secret Projects: Inside the Skunk Works. 1st Edn., Zenith Imprint, MBI Publishing Company, St. Paul, Minnesota, ISBN-10: 1610607287.

Kaufman, H.R., 1959. Installations at NASA Glenn.

Laming, T., 2000. Airbus A320. 1st Edn., Zenith Press.

Landis, T.R. and D.R. Jenkins, 2005. Lockheed Blackbirds. 1st Edn., Specialty Press, North Branch, ISBN-10: 1580070868, pp: 104.

Larson, G.C., 2015. Electrical Power Will Change the Look of Aviation. Air and Space Magazine.

Lu, P., L. Van Eykeren, E. van Kampen, C.C. de Visser and Q. P. Chu, 2016. Adaptive three-step kalman filter for air data sensor fault detection and diagnosis. J. Guidance, Control, Dynam., 39: 590-604. DOI: $10.2514 / 1 . G 001313$

Lu, P., L. Van Eykeren, E. van Kampen and Q.P. Chu, 2015. Selective-reinitialization multiple-model adaptive estimation for fault detection and diagnosis. J. Guidance, Control, Dynam., 38: 1409-1424.

DOI: $10.2514 / 1 . G 000587$

Mcewen, A., 2016. NASAFrosted dunes on Mars.

McKay, C.P., O.B. Toon and J.F. Kasting, 1991. Making Mars habitable. Nature, 352: 489-496.
Michell, J., 1784. On the means of discovering the distance, magnitude and c. of the fixed stars, in consequence of the diminution of the velocity of their light, in case such a diminution should be found to take place in any of them and such other data should be procured from observations, as would be farther necessary for that purpose. Philosophical Trans. Royal Society, 74: 35-57.

Mirsayar, M.M., V.A. Joneidi, R.V. Petrescu, F.I.T. Petrescu and F. Berto, 2017. Extended MTSN criterion for fracture analysis of soda lime glass. Eng. Fracture Mechan., 178: 50-59.

DOI: $10.1016 /$ j.engfracmech.2017.04.018

Murray, K., A. Marcos and L.F. Penin, 2010. Development and testing of a GNC-FDI filter for a reusable launch vehicle during ascent. Proceedings of the Guidance, Navigation and Control Conference, Aug. 2-5, AIAA, Toronto, Ontario Canada. DOI: $10.2514 / 6.2010-8195$.

Musk Elon, Explains the government we need on Mars. Retrieved from: https://stiri.md/article/stiinta/elonmusk-iti-explica-guvernarea-de-care-avem-nevoiepe-marte

NASA, 2013. NASA publishes Curiosity's surprising evidence that there was water on Mars.

Norris, G., 2010. Airbus A380: Superjumbo of the 21st Century. 1st Edn., Zenith Press.

Oberth, H., 1955. They come from outer space. Flying Saucer Rev., 1: 12-14.

Oppenheimer, J.R. and G.M. Volkoff, 1939. On massive neutron cores. Physical Rev., 55: 374-381.

Palumbo, R., G. Morani, M.D.S. Fumo C. Richiello and M. Di Donato et al., 2012. Concept study of an atmospheric reentry using a winged unmanned space vehicle. Proceedings of the 18th International Space Planes and Hypersonic Systems and Technologies Conference, Sept. 24-28, AIAA/3AF, Tours, France. DOI: $10.2514 / 6.2012-5857$

Patre, P. and S.M. Joshi, 2011. Accommodating sensor bias in MRAC for state tracking. Proceedings of the Guidance, Navigation and Control Conference, Aug. 8-11, AIAA, Portland, Oregon. DOI: $10.2514 / 6.2011-6605$.

Petrescu, F. and R. Petrescu, 1995a. Contributions to optimization of the polynomial motion laws of the stick from the internal combustion engine distribution mechanism. Bucharest.

Petrescu, F. and R. Petrescu, 1995b. Contributions to the synthesis of internal combustion engine distribution mechanisms. Bucharest.

Petrescu, F. and R. Petrescu, 1997a. Dynamics of cam mechanisms (exemplified on the classic distribution mechanism). Bucharest.

Petrescu, F. and R. Petrescu, 1997b. Contributions to the synthesis of the distribution mechanisms of internal combustion engines with Cartesian coordinate method. Bucharest. 
Petrescu, F. and R. Petrescu, 1997c. Contributions to maximizing polynomial laws for the active stroke of the distribution mechanism from internal combustion engines. Bucharest.

Petrescu, F. and R. Petrescu, 2000a. Synthesis of distribution mechanisms by the rectangular (cartesian) coordinate method. University of Craiova, Craiova.

Petrescu, F. and R. Petrescu, 2000b. The design (synthesis) of cams using the polar coordinate method (the triangle method). University of Craiova, Craiova.

Petrescu, F. and R. Petrescu, 2002a. Motion laws for cams. Proceedings of the 7th National Symposium with International Participation Computer Assisted Design (PAC' 02), Braşov, pp: 321-326.

Petrescu, F. and R. Petrescu, 2002b. Camshaft dynamics elements. Proceedings of the 7 th National Symposium with International Participation Computer Assisted Design (PAC' 02), Braşov, pp: 327-332.

Petrescu, F. and R. Petrescu, 2003. Some elements regarding the improvement of the engine design. Proceedings of the 8th National Symposium, Descriptive Geometry, Technical Graphics and Design, (GTD’03), Braşov, pp: 353-358.

Petrescu, F. and R. Petrescu, 2005a. The cam design for a better efficiency. Proceedings of the International Conference on Engineering Graphics and Design, (EGD’ 05), Bucharest, pp: 245-248.

Petrescu, F. and R. Petrescu, 2005b. Contributions at the dynamics of cams. Proceedings of the 9th IFToMM International Symposium on Theory of Machines and Mechanisms, (TMM' 05), Bucharest, Romania, pp: 123-128.

Petrescu, F. and R. Petrescu, 2005c. Determining the dynamic efficiency of cams. Proceedings of the 9th IFToMM International Symposium on Theory of Machines and Mechanisms, (TMM' 05), Bucharest, Romania, pp: 129-134.

Petrescu, F. and R. Petrescu, 2005d. An original internal combustion engine. Proceedings of the 9th IFToMM International Symposium on Theory of Machines and Mechanisms, (TMM' 05), Bucharest, Romania, pp: 135-140.

Petrescu, F. and R. Petrescu, 2005e. Determining the mechanical efficiency of Otto engine's mechanism. Proceedings of the 9th IFToMM International Symposium on Theory of Machines and Mechanisms, (TMM' 05), Bucharest, Romania, pp: 141-146.

Petrescu, F. and R. Petrescu, 2016c. An otto engine dynamic model. IJMP, 7: 038-048.

Petrescu, F.I. and R.V. Petrescu, 2011. Mechanical Systems, Serial and Parallel-Course (in Romanian). LULU Publisher, London, UK, ISBN-10: 978-1-4466-0039-9, pp: 124.
Petrescu, F.I. and R.V. Petrescu, 2012b. MecatronicaSisteme Seriale si Paralele. Create Space Publisher, USA, ISBN-10: 978-1-4750-6613-5, pp: 128.

Petrescu, F.I. and R.V. Petrescu, 2013. Cinematics of the 3R Dyad. Engevista, 15: 118-124.

Petrescu, F.I. and R.V. Petrescu, 2016a. Parallel moving mechanical systems kinematics, Engevista, 18: 455-491.

Petrescu, F.I. and R.V. Petrescu, 2016b. Direct and inverse kinematics to the Anthropomorphic Robots, Engevista, 18: 109-124.

Petrescu, F.I. and R.V. Petrescu, 2016d. Otto motor dynamics, GEINTEC, 6: 3392-3406.

Petrescu, F.I. and R.V. Petrescu, 2016e. Dynamic cinematic to a structure 2R. GEINTEC, 6: 3143-3154.

Petrescu, F.I., B. Grecu, A. Comanescu and R.V. Petrescu, 2009. Some mechanical design elements. Proceeding of the International Conference on Computational Mechanics and Virtual Engineering, (MEC' 09), Braşov, pp: 520-525.

Petrescu, F.I.T. and J.K. Calautit, 2016a. About nano fusion and dynamic fusion. Am. J. Applied Sci., 13: 261-266.

Petrescu, F.I.T. and J.K. Calautit, 2016b. About the light dimensions. Am. J. Applied Sci., 13: 321-325.

Petrescu, F.I.T. and R.V. Petrescu, 2012a. The Aviation History. Publisher: Books On Demand, ISBN-13: 978-3848230778.

Petrescu, F.I.T., A. Apicella, R. Aversa, R.V. Petrescu and J.K. Calautit et al., 2016c. Something about the mechanical moment of inertia. Am. J. Applied Sci., 13: 1085-1090.

Petrescu, F.I.T., A. Apicella, R.V. Petrescu, S.P. Kozaitis and R.B. Bucinell et al., 2016e. Environmental protection through nuclear energy. Am. J. Applied Sci., 13: 941-946.

Petrescu, R.V., R. Aversa, A. Apicella, F. Berto and S. Li et al., 2016d. Ecosphere protection through green energy. Am. J. Applied Sci., 13: 1027-1032.

Petrescu, R.V., R. Aversa, A. Apicella, M.M. Mirsayar and F.I.T. Petrescu, 2016a. About the gear efficiency to a simple planetary train. Am. J. Applied Sci., 13: 1428-1436.

Petrescu, R.V., R. Aversa, A. Apicella, M.M. Mirsayar and S. Kozaitis et al., 2017x. Current stage in the field of mechanisms with gears and rods. J. Mechatronics Robotics, 1: 47-57. DOI: $10.3844 /$ jmrsp.2017.47.57

Petrescu, R.V., R. Aversa, A. Apicella, M.M. Mirsayar and S. Kozaitis et al., 2017y. Geometry and inverse kinematic at the MP3R mobile systems. J. Mechatronics Robotics, 1: 58-65. DOI: $10.3844 / j m r s p .2017 .58 .65$ 
Petrescu, R.V., R. Aversa, A. Apicella, M.M. Mirsayar and S. Kozaitis et al., 2017z. Synthesis of optimal trajectories with functions control at the level of the kinematic drive couplings. J. Mechatronics Robotics, 1: 66-74. DOI: 10.3844/jmrsp.2017.66.74

Petrescu, R.V., R. Aversa, A. Apicella, M.M. Mirsayar and S. Kozaitis et al., 2017aa. The inverse kinematics of the plane system 2-3 in a mechatronic MP2R system, by a trigonometric method. J. Mechatronics Robotics, 1: 75-87. DOI: $10.3844 / j m r s p .2017 .75 .87$

Petrescu, R.V., R. Aversa, A. Apicella, M.M. Mirsayar and S. Kozaitis et al., 2017ab. Serial, anthropomorphic, spatial, mechatronic systems can be studied more simply in a plan. J. Mechatronics Robotics, 1: 88-97. DOI: 10.3844/jmrsp.2017.88.97

Petrescu, R.V., R. Aversa, A. Apicella, M.M. Mirsayar and S. Kozaitis et al., 2017ac. Analysis and synthesis of mechanisms with bars and gears used in robots and manipulators. J. Mechatronics Robotics, 1: 98-108. DOI: 10.3844/jmrsp.2017.98.108

Petrescu, R.V., R. Aversa, A. Apicella, M.M. Mirsayar and S. Kozaitis et al., 2017ad. Speeds and accelerations in direct kinematics to the MP3R systems. J. Mechatronics Robotics, 1: 109-117. DOI: $10.3844 /$ jmrsp.2017.109.117

Petrescu, R.V., R. Aversa, A. Apicella, M.M. Mirsayar and S. Kozaitis et al., 2017ae. Geometry and determining the positions of a plan transporter manipulator. J. Mechatronics Robotics, 1: 118-126. DOI: $10.3844 /$ jmrsp.2017.118.126

Petrescu, R.V., R. Aversa, A. Apicella, S. Li and G. Chen et al., 2016b. Something about electron dimension. Am. J. Applied Sci., 13: 1272-1276.

Petrescu, R.V., R. Aversa, B. Akash, F. Berto and A. Apicella et al., 2017n. The modern flight. J. Aircraft Spacecraft Technol., 1: 224-233. DOI: $10.3844 /$ jastsp.2017.224.233

Petrescu, R.V., R. Aversa, B. Akash, F. Berto and A. Apicella et al., 2017o. Sustainable energy for aerospace vessels. J. Aircraft Spacecraft Technol., 1: 234-240. DOI: 10.3844/jastsp.2017.234.240

Petrescu, R.V., R. Aversa, B. Akash, F. Berto and A. Apicella et al., 2017p. Unmanned helicopters. J. Aircraft Spacecraft Technol., 1: 241-248. DOI: $10.3844 /$ jastsp.2017.241.248

Petrescu, R.V., R. Aversa, B. Akash, F. Berto and A. Apicella et al., 2017q. Project HARP. J. Aircraft Spacecraft Technol., 1: 249-257. DOI: $10.3844 /$ jastsp.2017.249.257

Petrescu, R.V., R. Aversa, B. Akash, F. Berto and A. Apicella et al., 2017r. Presentation of romanian engineers who contributed to the development of global aeronautics-part I. J. Aircraft Spacecraft Technol., 1: 258-271.

DOI: $10.3844 /$ jastsp.2017.258.271
Petrescu, R.V., R. Aversa, B. Akash, F. Berto and A. Apicella et al., 2017s. A first-class ticket to the planet mars, please. J. Aircraft Spacecraft Technol., 1: 272-281. DOI: 10.3844/jastsp.2017.272.281

Petrescu, R.V., R. Aversa, B. Akash, F. Berto and A. Apicella et al., 2017t. Forces of a 3R robot. J. Mechatronics Robotics, 1: 1-14. DOI: $10.3844 /$ jmrsp.2017.1.14

Petrescu, R.V., R. Aversa, B. Akash, F. Berto and A. Apicella et al., 2017u. Direct geometry and cinematic to the MP-3R systems. J. Mechatronics Robotics, 1: 15-23. DOI: 10.3844/jmrsp.2017.15.23

Petrescu, R.V., R. Aversa, B. Akash, F. Berto and A. Apicella et al., 2017v. Dynamic elements at MP3R. J. Mechatronics Robotics, 1: 24-37. DOI: $10.3844 /$ jmrsp.2017.24.37

Petrescu, R.V., R. Aversa, B. Akash, F. Berto and A. Apicella et al., 2017w. Geometry and direct kinematics to MP3R with $4 \times 4$ operators. J. Mechatronics Robotics, 1: 38-46. DOI: $10.3844 /$ jmrsp.2017.38.46

Petrescu, R.V., R. Aversa, B. Akash, J. Corchado and F. Berto et al., 2017e. Our universe. J. Aircraft Spacecraft Technol., 1: 69-79. DOI: 10.3844/jastsp.2017.69.79

Petrescu, R.V., R. Aversa, B. Akash, J. Corchado and F. Berto et al., 2017f. What is a UFO? J. Aircraft Spacecraft Technol., 1: 80-90. DOI: $10.3844 /$ jastsp.2017.80.90

Petrescu, R.V., R. Aversa, B. Akash, J. Corchado and F. Berto et al., 2017g. About bell helicopter FCX-001 concept aircraft-a short review. J. Aircraft Spacecraft Technol., 1: 91-96. DOI: $10.3844 /$ jastsp.2017.91.96

Petrescu, R.V., R. Aversa, B. Akash, J. Corchado and F. Berto et al., 2017h. Home at airbus. J. Aircraft Spacecraft Technol., 1: 97-118. DOI: 10.3844/jastsp.2017.97.118

Petrescu, R.V., R. Aversa, B. Akash, J. Corchado and F. Berto et al., 2017i. Airlander. J. Aircraft Spacecraft Technol., 1: 119-148. DOI: $10.3844 /$ jastsp.2017.119.148

Petrescu, R.V., R. Aversa, B. Akash, J. Corchado and F. Berto et al., 2017j. When boeing is dreaming-a review. J. Aircraft Spacecraft Technol., 1: 149-161. DOI: 10.3844 /jastsp.2017.149.161

Petrescu, R.V., R. Aversa, B. Akash, J. Corchado and F. Berto et al., 2017k. About Northrop Grumman. J. Aircraft Spacecraft Technol., 1: 162-185. DOI: 10.3844 /jastsp.2017.162.185

Petrescu, R.V., R. Aversa, B. Akash, J. Corchado and F. Berto et al., 20171. Some special aircraft. J. Aircraft Spacecraft Technol., 1: 186-203. DOI: $10.3844 /$ jastsp.2017.186.203

Petrescu, R.V., R. Aversa, B. Akash, J. Corchado and F. Berto et al., 2017m. About helicopters. J. Aircraft Spacecraft Technol., 1: 204-223. DOI: $10.3844 /$ jastsp.2017.204.223 
Petrescu, R.V., R. Aversa, B. Akash, R. Bucinell and J. Corchado et al., 2017a. Modern propulsions for aerospace-a review. J. Aircraft Spacecraft Technol., 1: 1-8. DOI: $10.3844 /$ jastsp.2017.1.8

Petrescu, R.V., R. Aversa, B. Akash, R. Bucinell and J. Corchado et al., 2017b. Modern propulsions for aerospace-part II. J. Aircraft Spacecraft Technol., 1: 9-17. DOI: 10.3844/jastsp.2017.9.17

Petrescu, R.V., R. Aversa, B. Akash, R. Bucinell and J. Corchado et al., 2017c. History of aviation-a short review. J. Aircraft Spacecraft Technol., 1: 30-49. DOI: 10.3844 jastsp.2017.30.49

Petrescu, R.V., R. Aversa, B. Akash, R. Bucinell and J. Corchado et al., 2017d. Lockheed martin-a short review. J. Aircraft Spacecraft Technol., 1: 50-68. DOI: 10.3844 jastsp.2017.50.68

Sagan, C., 1989. Broca's Brain. Ed. Politica Bucuresti.

Science Alert, 16 SEP 2016. Mars had liquid water a billion years longer than we even thought possible. Sci. Alert. https://www.sciencealert.com/mars-hadliquid-water-1-billion-years-longer-than-we-eventhought-possible

Sevil, H.E. and A. Dogan, 2015. Fault diagnosis in air data sensors for receiver aircraft in aerial refueling. J. Guidance, Control, Dynam., 38: 1959-1975. DOI: 10.2514/1.G000527

Sherson, J.F., H. Krauter, RK. Olsson, B. Julsgaard and K. Hammerer et al., 2006. Quantum teleportation between light and matter. Nature, 443: 557-560. DOI: 10.1038 /nature05136

Tosca, N., A.H Knoll, SM. McLennan and 2008. Water activity and the challenge for life on early Mars. Science, 320: 1204-1207.

DOI: $10.1126 /$ science. 1155432
Ward, TA., 2010. Aerospace Propulsion Systems. 1st Edn., Wiley Publisher, ISBN: 9780470824979.

Williams, D.R., 1995. Saturnian satellite fact sheet. NASA. https://nssdc.gsfc.nasa.gov/planetary/factsheet/satur niansatfact.html

\section{Source of Figures}

\section{Fig. 1:}

http://a1.a4w.ro/assets/yoda/2013/06/01/image_galleries/ 14672/nasa-publica-dovada-surprinsa-de-curiosity-cape-marte-a-existat-apa.jpg

Fig. 2: http://www.descopera.ro/stiinta/15713988-pemarte-a-existat-apa-cu-miliarde-de-ani-inainte-cacercetatorii-sa-considere-posibil-fenomenul

Fig.3:

https://en.wikipedia.org/wiki/Life_on_Mars\#/media/File: PIA19673-Mars-AlgaCrater-ImpactGlassDetectedMRO-20150608.jpg

Fig. 4:

https://www.nasa.gov/multimedia/imagegallery/image_f eature_857.html

Fig. 5:

https://phys.org/news/2017-08-image-world-snowydunes-mars.html

Fig. 6:

https://phys.org/news/2016-06-image-frosted-dunesmars.html\#nRlv

Fig. 7:

https://www.stiintaonline.ro/planul-lui-elon-musk-decolonizare-planetei-marte/ 